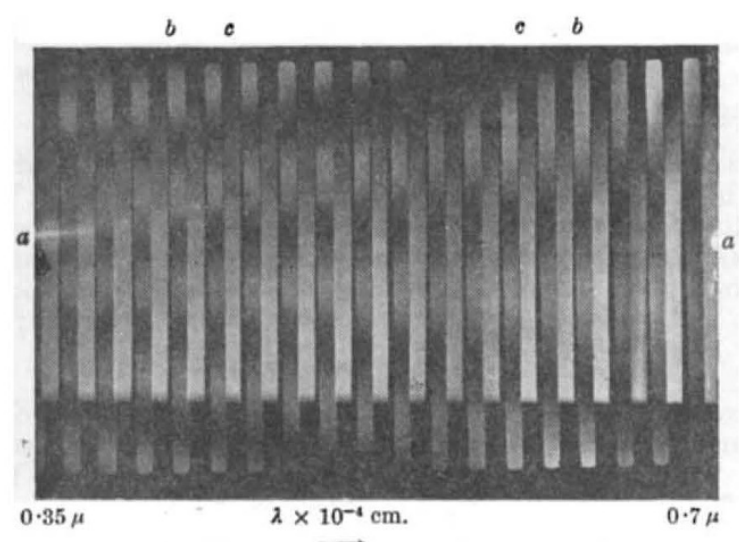

Fig. 3. (a) Fiducial line; $(b)$ vertical bands of variable intensity; (c) adjacent graded intensity

Experiments have so far been carried out in the wave-length range $0 \cdot 35-0 \cdot 7 \mu$ with gold and aluminium specimens of known dispersion (measured on the senior author's photo-electric apparatus ${ }^{1}$ ), and good agreement was obtained. The estimated accuracy is about 2 per cent, but improvements now being made are expected to increase the accuracy and reduce the exposure time.

One of us (B. G. C.) is indebted to the Department of Scientific and Industrial Research for the award of a maintenance grant.

1 Bor, Nature, 139, 716 (1937). Bor, Hobson-and Wood, Proc. Phys. Soc., 51, 932 (1939).

\section{GROUND SUBSTANCE OF THE MESENCHYME AND HYALURONIDASE}

A CONFEREXCE devoted to the "Ground Substanco of the Mesenchyme and Hyaluronidase" was grganised by Dr. F. Duran-Reynals with the co-operation of Dr. E. D. Goldsmith and was held during December 3-4 under the sponsorship of tho New York Academy of Sciences.

The programme concerned itself with all phases of current research pertaining to acid mucopolysaccharides and hyaluronidase, the most important of the group of substances known as spreading factors. Histochemical, electron microscope, biochemical, bacteriological, endocrinological and clinical findings were reported.

Hyaluronidase is widely distributed in Nature. It is found in male germ cells, in pathogenic bacteria, such as streptococci and pneumococci, in insects, in fishes, and in the poison glands of several venomous reptiles. Although produced by such diverse organisms, the function of the enzyme is the same in all cases; but the results are totally different. The function of hyaluronidase is to attack the cementing mucoid substance of the connective tissue. By attacking this cementing substance, the enzyme 'dissolves' it and opens the way for any material which may penetrate the body with it.

Thus, the spreading factor associated with the male germ cells dissolves the cementing material surrounding the female germ cells and makes fertilization possible. (The adhesive quality of mucopolysaccharides of ovarian follicular fluid clumps the granulosa cells around the discharged ovum until acted upon by hyaluronidase from the sperm.) When the factor comes from a bacterium it facilitates invasive infection, and when hyaluronidase is injected with a therapeutic agent, it speeds and enhances the action of such agents.

The study of the action of the enzyme on the cement substance has served to explain an important factor in the mechanism of infection, namely, spreading in the organism of poisons or infectious agents. Equally it has provided a tool for the clinician, since it promotes the spreading of therapeutic substances in the organism. Infections may thus be fought with their own weapons.

The following papers dealing with more specific aspects were read at the conference.

The enhancement of the capacities for growth and invasion of a mouse transplantable squamous cell carcinoma by the local injection of hyaluronidase from testis (W. L. Simpson, Detroit Institute of Cancer Research).

The facilitation of absorption of subcutaneously injected lactate-sodium-glucose solutions with a diminution in pain. It should prove to be extremely useful in hypodermoclysis (C. L. Burket and P. Gyorgy, University of Pennsylvania).

Hyaluronidase enhances the penetration as well as the spreading of drugs. Further, it exhibits very low toxicity (J. Seifter, Wyeth Institute of Applied Biochemistry).

Hyaluronidase reported to be effective in the spreading of the anæsthetic action of Iocal anæsthetics. Certain difficulties encountered in nerve block techniques in regions like the mandible may be overcome by the addition of hyaluronidase to the procaine-opinephrine mixture (C. H. Kirby, J. P. Looby and J. E. Ekenhoff, School of Medicine and Dentistry, University of Pennsylvania).

Dr. D. H. Sprunt (University of Tennessee) and Dr. M. Lurie (Henry Phipps Institute) emphasized the importance of the connective tissue ground-plasm in infection (tuberculosis, D. Lurie). Female sex hormone increases the turgidity of the connective tissue elements and reduces capillary fragility. Estrogens retard the progress of tuberculosis, chiefly by reducing the permeability of the connective tissue, whereas gonadotrophin enhances the progress of the disease, primarily, by increasing the permeability. It is noteworthy that some years ago Thomas and Duran-Reynals accelerated the progress of tuberculosis with hyaluronidase.

Additional findings by Drs. F. Duran-Reynals, G. Van Wagenen, H. Bunting and J. Opsahl (Yale University School of Medicine) pertaining to the relationship between the cestrogens, adreno-cortical hormone and the ground substance and hyaluronidase were reported.

Drs. C. Ragan and K. Meyer (College of Physicians and Surgeons, Columbia University), in their report on the possible connexion between hyaluronidase and rheumatic diseases, disclosed that the pathogenesis of the rheumatic diseases is obscure. Apparently, the disease process is localized in the connective and particularly in the interfibrillar material, which is composed in part of one or both of the mucopolysaccharides-chondroitin sulphuric acid and hyaluronic acid. Many micro-organisms produce hyaluronidase; but only two, Group $A$ and $C$ hæmolytic streptococci, produce hyaluronic acid. The highest concentration of hyaluronic acid in the mammal is found in the synovial fluid (in the joint). In normal human joint 
fluid the hyaluronic acid exists in a highly polymerized form ; in rheumatoid arthritis, the hyaluronic acid is depolymerized, and the extent of depolymerization varies with the activity of the disease process.

Dr. M. C. Chang and Dr. N. T. Werthessen (Worcester Foundation for Experimental Biology) took issue with the conclusions of Dr. Raphael Kurzrock to the effect that hyaluronidase is a valuable adjunct in the treatment of infertility. Dr. Chang and Dr. Werthessen attributed Dr. Kurzrock's success to his excellent timing in determining the date of ovulation.

The conference closed on the note that the spreading substances and ground-plasm are of great significance. Much remains to be ascertained; and a uniform system of units should be devised.

$$
2216
$$

E. D. Goldsmith

\section{SCIENCE MASTERS' ASSOCIATION}

\section{ANNUAL MEETING}

$\mathrm{T}$ HE forty-sixth annud meeting of the Seience Masters' Associati 9 f was held during January 4-7 in London at 19 Koyal College of Science. Prof. F. R. Winton University College, London, in the presidential address on "Specialization", suggested reastens for the undue specialization of school science, condending that boys are driven by a sense of insecurity into scientific studies in their search for truth, but in these studies they seldom meet with experience in the selection and recognition of the vital factors in a problem; and, further, one of the most important approaches, the statistical method, is neglected. Turning to a more detailed consideration of biology teaching, Prof. Winton criticized its subjectmatter as being too often narrow and unrelated to human experience; he made a plea for more experimental work in human physiology, and proposed that reform might be brought about through a review of school courses by joint action of the Science Masters' Association and the Biological Council, with medical and psychological representatives.

On the subject of "Phase Contrast Microscopy and the Study of the Living Cell", Dr. Arthur Hughes, after an admirably simple account of the underlying principles, explained how this new technique has made possible the direct study of living cells in tissue cultures. Remarkable results, such as the identification of chromosomes in the resting stage and the formation of tetraploid nuclei, were illustrated by Dr. Hughes' own film of cell division in the spleen cells of the mouse.

In a lecture on "Why Schools should use M.K.S. Electrical Units", Prof. G. H. Rawcliffe pointed out that there is no justification for the present complexity of electrical units. This complexity arose because those who first suggested the units did not realize that the systems involved the permeability and the permittivity of air in addition to the centimetre, gram and second. The simplest unified system is the Metre-Kilogram-Second system, which erects the volt, the ampere and the units dependent on them into an absolute system ; this has the advantage of being the system that electrical engineers use, and prevents the confusion between $B$ and $H$ in magnetism and that between $D$ and $E$ in electrostatics.

Sir Charles Goodeve discussed the "Making of Iron and Steel". He referred to the huge amounts of ironstone, coke, limestone and other raw materials used yearly for this purpose, and the selection and control of these by scientific methods. But the human intake which parallels this often lacks preparation, not only in knowledge of the elementary principles of the industry, but also in knowledge of the extremely wide range of trades, crafts and skills that the industry needs to keep it in operation.

The lecture on "The Perception of Light and Colour", by Dr. W. D. Wright, was illustrated by a wealth of demonstrations. Simple experiments were described in which the sensitivity of the eye to light could be compared under various conditions, and the phenomena used, if required, to introduce the idea both of the adaptation of the organism to its environment in biology and the quantum nature of light in physics, as well as the practical problems of vision involved in night flying, driving at night, etc. A method of approach was suggested by which instruction about colour by the art master might be co-ordinated with that by the science master.

Prof. E. D. Hughes, of University College, London, introduced his lecture on "Recent Theories of Organic Chemistry" with a general survey of the application of modern valency theory to problems relating to the structure and reactions of typical groups of organic compounds. Ideas on partial ionic character and resonance hybrids provided explanations of apparently contradictory results of hydrolysis of esters and the reactions of carbonyl and carboxylic groups.

Dr. B. Wheeler Robinson, superintendent of the Physics Division of the National Physical Laboratory, in dealing with "Physics at the N.P.L.", explained how this Laboratory has responsibility for the maintenance of physical standards, for special tests and investigations for the benefit of industry, and for original research arising therefrom. The Physics Division, one of ten divisions which comprise the Laboratory, deals mainly with radiology, heat measurements and acoustics. The measurement of the temperature of molten steel and the thermal conductivity of a building panel were described in more detail, and Dr. Robinson showed how the methods in practice differ from the text-book accounts of them.

"English in the Science Course" formed the subject. of a lecture by Dr. D. C. Collins. He pointed out that style is not extraneous ornament; it comes from clear thinking. Words are important to the scientific man as a means by which he explains to 'everyman' the scientific picture of the material world. The difficulty of using words, which is a modern phenomenon, is perhaps due to the decay of the study of the classies, which, inter alia, gave a training in the writing of English, and modern courses in English have not completely taken the place of the study of the classics. Dr. Collins suggested possible ways of remedying the deficiency and developing the required. skill of writing.

Dr. E. A. R. Ennion described various methods in use at Flatford Mill Field Centre, where he is warden, for the training of students in field-work of all kinds (natural history, geography, local history and rural surveys) and for the initiation and promotion of amateur research. Student groups covered comprise teachers themselves, training college and fifth or sixth form school classes coming with or without teachers and either individually or as corporate parties. The basic assumption was that there is a place for properly conducted amateur research. It is quite feasible for students to acquire tho necessary com. 